\title{
Classifying Returns as Extreme: European Stock and Bond Markets
}

\author{
Charlotte Christiansen
}

CREATES Research Paper 2013-37 


\title{
Classifying Returns as Extreme: European Stock and Bond Markets*
}

\author{
Charlotte Christiansen ${ }^{\dagger}$ \\ CREATES, Aarhus University
}

November 1, 2013

${ }^{*}$ I acknowledge financial support from CREATES (Center for Research in Econometric Analysis of Time Series) which is funded by the Danish National Research Foundation (DNRF78).

$\dagger$ Aarhus University, School of Business and Social Sciences, Department of Economics and Business, CREATES, Fuglesangs Alle 4, 8210 Aarhus V, Denmark. Phone: +45 8716 5576. Email: CChristiansen@creates.au.dk. 


\title{
Classifying Returns as Extreme: European Stock and Bond Markets
}

\begin{abstract}
I consider the stock and bond markets of 14 EU countries. I use two classification schemes for defining extreme returns: One, the existing univariate classification scheme which considers each market separately. Two, the new multivariate classification scheme that considers all the markets jointly whereby a shorter sample period is needed. For the bond markets the simultaneous extreme return variable (used for analyzing integration and contagion of financial markets) is not statistically different for the two schemes. For the stock markets there are differences, but they are disappearing in the most recent sample period.
\end{abstract}

Keywords: European stock markets; European bond markets; Extreme returns; Financial crisis; Integration of financial markets

JEL Classifications: G01; G12; G15 


\section{Introduction}

The previous literature investigates when asset returns are extreme, that is when there are large negative returns on a given financial market. Also, the previous literature studies which explanatory variables explain the simultaneous occurrence of extreme returns across several financial markets. A long sample period is needed because only the $5 \%$ smallest returns are classified as being extreme. In this paper, I provide a new classification scheme for returns being extreme that requires a shorter sample period.

So far, returns are classified as being extreme by considering each asset market separately. I denote this for the univariate classification. That is, to classify whether a return on a particular stock market (say Germany) is extreme on a given day, only the time series of returns for that particular stock market (Germany) is investigated. Here, I advocate considering several similar asset markets simultaneously when classifying extreme returns. I denote this for the multivariate classification. For the German stock market example, I use all the stock markets of the old EU countries to classify German stock returns as extreme. In this way it is possible to apply data from a much shorter sample period compared to the univariate classification scheme.

Bae, Karolyi and Stulz (2003) provide a new approach to measuring financial contagion. They use multinomial logit regressions for simultaneous extreme returns, that is they explain the joint occurrence of extreme returns at various stock markets. The classification of extreme returns on the individual markets only depends on the return distribution on that particular market. Christiansen and Ranaldo (2009) build on the Bae et al. (2003) terminology to investigate the integration of the new and old EU member states' stock markets. Boyson, Stahel and Stulz (2010) also build on the Bae et al. (2003) terminology to investigate the contagion in the hedge fund market. Cumperayot, Keijzer and Kouwenberg (2006) consider simultaneous equations probit models for extreme stock returns and extreme currency returns. Martwat, Kole and van Dijk (2009) use ordered logit regressions 
to distinguish between local, regional, and global crashes where crashes are defined as simultaneous extreme returns.

In this paper I consider the stock and bond markets of 14 old EU member states. I use two classification schemes for defining extreme returns, namely first the univariate classification scheme of the previous literature and second the new multivariate classification scheme. I show that the two classification schemes give rise to statistically different simultaneous extreme return variables for stock markets and similar variables for bond markets. In the most recent time period after the onset of the financial crisis, the two classification schemes give similar results, also for the stock markets.

The remaining part of the paper is organized as follows. First, I introduce the stock and bond data. Second, I provide details about the classification schemes. Third, I show the empirical results for the European stock markets followed by the European bond markets. Finally, I conclude.

\section{Data}

I consider the following 14 old EU member states: Austria, Belgium, Denmark, Finland, France, Germany, Greece, Ireland, Italy, the Netherlands, Portugal, Spain, Sweden, and the UK. I use local currency daily log-returns from total return indices obtained from DataStream.

The DataStream stock indices cover the period from 1990 through 2012, providing 5,999 daily stock return observations for each country or a total of 83,986 daily stock return observations (14 times 5,999). The DataStream benchmark 10-year government bond total return index cover a shorter period from 2000 to 2012, providing 3,391 daily bond return observations for each country or a total of 47,474 bond observations.

Table 1 shows the descriptive statistics for the two data sets. The mean daily stock returns are small and the means are not significantly different across countries. The standard deviations are about the same size but significantly different. The stock return series are strongly leptokurtic but close 
to being symmetric. Normality is always rejected by the Jarque and Bera (1980) test. For the bond returns the means are even smaller and still not significantly different across countries. There is more variability in the standard deviations. For a few countries, the returns have positive skewness and for most countries the returns are strongly leptokurtic. Normality is always rejected.

\section{Classification Schemes}

The classification schemes are exemplified for the stock markets. The bond market definitions follow straight forward.

\subsection{Univariate Classification}

First, I follow the previous literature beginning with Bae et al. (2003) and use their classification scheme. I denote this for the univariate classification scheme. A return for a given country (say Germany) is extreme if it is below the $5 \%$ threshold of the distribution of German stock returns for the entire sample period, i.e. the $5 \%$ lowest returns are classified as being extreme. The same procedure applies for the other 13 countries' stock markets.

\subsection{Multivariate Classification}

Second, I introduce a new classification scheme, namely the multivariate classification scheme. Here the stock returns for all 14 countries are pooled. Then the extreme returns are those that are below the $5 \%$ threshold of the pooled distribution of the stock returns. Using the multivariate classification scheme implies that for some countries there will be more than $5 \%$ extreme returns and for others less than $5 \%$. Extreme is seen from the perspective of the combined European stock markets. 


\subsection{Simultaneous Extreme Returns}

I investigate the variable that counts the number of countries that have extreme stock returns simultaneously for each day in the sample period. The simultaneous extreme return variable takes on integer values between zero (no countries have extreme returns) and 14 (all countries have extreme returns). The simultaneous extreme return variable will be different for the two classification schemes. This variable has been the explained variable when analyzing integration and contagion of financial markets in the previous literature.

\section{Extreme Stock Returns}

Table 2 shows the number of extreme stock returns for both the univariate and multivariate classification. For most countries the number of extreme returns is significantly smaller using the multivariate classification scheme compared to the univariate scheme. For Finland, Greece, Italy, and Sweden the number of extreme returns is significantly larger. Only for four countries (France, Ireland, Netherlands, and Spain) is the number of extreme returns not significantly different for the two schemes.

Table 3 shows the frequency of the simultaneous extreme returns using both classification schemes. Using the multivariate classification, there are fewer days without any extreme returns and more days with only one extreme return. The proportion of days with two or more extreme returns is fairly close for the two classification schemes. Table 4 shows the cross tabulation of the simultaneous extreme returns for the two schemes. Here I combine days with at least three extreme returns into one category. As expected, the two schemes are not statistically independent. Importantly, the two schemes are significantly different.

I consider the sub-sample behavior of the simultaneous extreme return variables, namely by considering the period since the onset of the recent financial crisis separately (since 2008). Here, I cannot reject that the two 
schemes are identical. For the period before the financial crisis (1990 to 2007), the two schemes are significantly different. So, it is mainly due to differences in the first part of the sample period that the two schemes lead to differences for the simultaneous extreme stock return variable.

\section{$5 \quad$ Extreme Bond Returns}

The corresponding results for extreme bond returns are shown in separate panels in Tables 2-4. Table 2 shows that only for Italy and the UK is the multivariate classification scheme not significantly different from the univariate scheme. For most countries the multivariate classification scheme defines fewer extreme returns (same as for stocks). For Greece, Ireland, Portugal, and Spain are there significantly more extreme returns using the multivariate classification scheme. Those are the countries which have experienced the sovereign debt crisis.

The simultaneous extreme bond returns in Table 3 show the same pattern as for the stock market. The cross tabulation in Table 4 of the simultaneous extreme bond returns shows that the two schemes are not independent (same as for stocks). In contrast to the stock markets, it cannot be rejected that the two schemes are identical. This also applies for the sub periods before and after the onset of the financial crisis. So, for bond markets it is of no consequence whether I use the univariate or the multivariate classification scheme for investigating integration and contagion issues. For bond markets it is thus feasible to use a shorter time period when classifying extreme returns, simply by pooling the information from all the European bond markets.

\section{Conclusion}

In this paper I investigate the classification of extreme returns for EU stock and bond markets. So far, the literature has considered the classification of extreme returns for each country separately. In this paper I show that in 
particular for bond markets it is relevant to consider all the EU bond markets jointly, whereby a shorter sample period is called for. For the most recent time period (since 2008) the two classification schemes give rise to similar simultaneous extreme return variables, also for the EU stock markets.

Future research could investigate if the multivariate classification scheme is also feasible in other geographic markets than the European.

\section{References}

Bae, K.-H., Karolyi, G. A. and Stulz, R. M.: 2003, A New Approach to Measuring Financial Contagion, Review of Financial Studies 16(3), 717763.

Boyson, N. M., Stahel, C. W. and Stulz, R. M.: 2010, Hedge Fund Contagion and Liquidity Shocks, Journal of Finance 65(5), 1789-1816.

Christiansen, C. and Ranaldo, A.: 2009, Extreme Coexceedances in New EU Member States' Stock Markets, Journal of Banking and Finance 33, 1048-1057.

Cumperayot, P., Keijzer, T. and Kouwenberg, R.: 2006, Linkages between Extreme Stock Market and Currency Returns, Journal of International Money and Finance 25, 528-550.

Jarque, C. M. and Bera, A. K.: 1980, Efficient Tests for Normality, Economics Letters 6, 255-259.

Martwat, T., Kole, E. and van Dijk, D.: 2009, Contagion as a Domino Effect in Global Stock Markets, Journal of Banking and Finance 33, 1996201295 . 
2013-19: $\quad$ Asger Lunde and Kasper V. Olesen: Modeling and Forecasting the Volatility of Energy Forward Returns - Evidence from the Nordic Power Exchange

2013-20: $\quad$ Anders Bredahl Kock: Oracle inequalities for high-dimensional panel data models

2013-21: $\quad$ Malene Kallestrup-Lamb, Anders Bredahl Kock and Johannes Tang Kristensen: Lassoing the Determinants of Retirement

2013-22: Johannes Tang Kristensen: Diffusion Indexes with Sparse Loadings

2013-23: $\quad$ Asger Lunde and Anne Floor Brix: Estimating Stochastic Volatility Models using Prediction-based Estimating Functions

2013-24: Nima Nonejad: A Mixture Innovation Heterogeneous Autoregressive Model for Structural Breaks and Long Memory

2013-25: Nima Nonejad: Time-Consistency Problem and the Behavior of US Inflation from 1970 to 2008

2013-26: Nima Nonejad: Long Memory and Structural Breaks in Realized Volatility: An Irreversible Markov Switching Approach

2013-27: $\quad$ Nima Nonejad: Particle Markov Chain Monte Carlo Techniques of Unobserved Compdonent Time Series Models Using Ox

2013-28: $\quad$ Ulrich Hounyo, Sílvia Goncalves and Nour Meddahi: Bootstrapping preaveraged realized volatility under market microstructure noise

2013-29: Jiti Gao, Shin Kanaya, Degui Li and Dag Tjøstheim: Uniform Consistency for Nonparametric Estimators in Null Recurrent Time Series

2013-30: $\quad$ Ulrich Hounyo: Bootstrapping realized volatility and realized beta under a local Gaussianity assumption

2013-31: Nektarios Aslanidis, Charlotte Christiansen and Christos S. Savva: Risk-Return Trade-Off for European Stock Markets

2013-32: Emilio Zanetti Chini: Generalizing smooth transition autoregressions

2013-33: Mark Podolskij and Nakahiro Yoshida: Edgeworth expansion for functionals of continuous diffusion processes

2013-34: Tommaso Proietti and Alessandra Luati: The Exponential Model for the Spectrum of a Time Series: Extensions and Applications

2013-35: Bent Jesper Christensen, Robinson Kruse and Philipp Sibbertsen: A unified framework for testing in the linear regression model under unknown order of fractional integration

2013-36: $\quad$ Niels S. Hansen and Asger Lunde: Analyzing Oil Futures with a Dynamic Nelson-Siegel Model

2013-37: Charlotte Christiansen: Classifying Returns as Extreme: European Stock and Bond Markets 